\title{
Electrocaloric effect of alkali co-substituted $\mathrm{Sr}_{0.6} \mathrm{Ba}_{0.4} \mathrm{Nb}_{2} \mathrm{O}_{6}$ ceramics
}

\author{
Arif Kurnia $^{\text {a }}$, Emriadi ${ }^{a}$, Nandang Mufti ${ }^{\text {, }}$ Zulhadjri ${ }^{a}$, Umut Adem ${ }^{c, *}$ \\ a Department of Chemistry, Faculty of Mathematics and Natural Sciences, Universitas Andalas, Kampus Limau Manis, Padang, 25163, Indonesia \\ ${ }^{\mathrm{b}}$ Department of Physics, Faculty of Mathematics and Natural Sciences, Universitas Negeri Malang, Jl. Semarang 5, Malang, 65145, Indonesia \\ ${ }^{\mathrm{c}}$ Department of Materials Science and Engineering, Izmir Institute of Technology, Urla, 35430, Izmir, Turkey
}

\section{A R T I CLE INFO}

\section{Article history:}

Received 1 May 2020

Received in revised form 2 June 2020

Accepted 18 June 2020

Available online xxx

\section{Keywords}

Electrocaloric effect

Strontium barium niobate

Tetragonal tungsten bronze

Cation disorder

\begin{abstract}
A B S T R A C T
We have investigated the electrocaloric properties of $\mathrm{K}^{+}$and $\mathrm{Na}^{+}$co-substituted $\mathrm{Sr}_{0.6} \mathrm{Ba}_{0.4} \mathrm{Nb}_{2} \mathrm{O}_{6}$ (SBN) ceramics using the indirect method. Tetragonal tungsten bronze $\left(\mathrm{K}_{0.5} \mathrm{Na}_{0.5}\right)_{2 x}\left(\mathrm{Sr}_{0.6} \mathrm{Ba}_{0.4}\right)_{5-x} \mathrm{Nb}_{10} \mathrm{O}_{30}$ (KNSBN) with $x=0.24$ was synthesized using dual-step sintering. Despite the low amount, $\mathrm{K}^{+}$and $\mathrm{Na}^{+}$co-substitution resulted in normal ferroelectric behaviour, showing no significant shift in the dielectric maximum temperature of $111{ }^{\circ} \mathrm{C}$ with increasing frequency. Maximum electrocaloric temperature change $(\Delta \mathrm{T})$ of $0.3 \mathrm{~K}$ was observed at an electric field of $30 \mathrm{kV} / \mathrm{cm}(\Delta \mathrm{E})$ yielding the largest electrocaloric responsivity $(\Delta \mathrm{T} / \Delta \mathrm{E})$ among SBN based ceramics. This relatively large value is in agreement with the larger pyroelectric coefficient of KNSBN compared to SBN based ceramics.
\end{abstract}

(C) 2020

\section{Introduction}

Recently, solid state cooling based on caloric materials received a lot of attention as an alternative for the conventional vapor compression based cooling technology due to its advantages such as lack of hazardous gases, compact size and high theoretical efficiency of the cooling cycle [1-4]. Among the caloric materials, electrocaloric materials are dielectric materials that show change in their dipolar entropy when an electric field is applied or withdrawn. The change of dipolar entropy upon the application of electric field results in a temperature change under adiabatic conditions; this phenomenon is called the electrocaloric effect $[1,5]$. The electrocaloric effect is large around the phase transitions in ferroelectric as well as antiferroelectric materials such as ferroelectric to paraelectric [6], antiferroelectric to ferroelectric [7] or ferroelectric to ferroelectric [8] phase transitions where large entropy changes take place. Ceramic and polymer ferroelectric materials in bulk as well as in thin and thick ceramic film forms are studied as electrocaloric materials [4]. Bulk ceramics have larger cooling capacity and larger electrocaloric responsivity than thin film counterparts, suited for the medium to large scale refrigeration systems [9]. Despite the large electrocaloric effect reported for $\mathrm{Pb}$-based systems, due to the toxicity of $\mathrm{Pb}$, research is also focused on $\mathrm{Pb}$-free ferroelectrics for electrocaloric cooling applications. $\mathrm{Pb}$-free systems that are extensively explored include $\mathrm{BaTiO}_{3}$ based systems such as $\mathrm{BaTi}_{1-x} \mathrm{Sn}_{x} \mathrm{O}_{3}[10$

\footnotetext{
* Corresponding author.

E-mail address: umutadem@iyte.edu.tr (U. Adem)
}

], $\mathrm{BaHf}_{x} \mathrm{Ti}_{1-x} \mathrm{O}_{3}$ [6], $\mathrm{Ba}_{0.8} \mathrm{Sr}_{0.2} \mathrm{Ti}_{1-x} \mathrm{Zr}_{x} \mathrm{O}_{3}$ [11] as well as $\mathrm{Na}_{0.5} \mathrm{Bi}_{0.5} \mathrm{TiO}_{3}$ [12] and $\mathrm{K}_{0.5} \mathrm{Na}_{0.5} \mathrm{NbO}_{3}$ [13] based materials.

Tetragonal tungsten bronze (TTB) ceramics have good dielectric, ferroelectric, pyroelectric and piezoelectric properties and versatile applications in electro-optics [14-17]. TTB structure with the general formula (A1) $)_{2}(\mathrm{~A} 2)_{4} \mathrm{C}_{4} \mathrm{~B}_{10} \mathrm{O}_{30}$, consists of $\mathrm{BO}_{6}$ octahedra linked by corner sharing, thereby creating three different interstitial sites for the A-site cations (two A1 (square), four A2(pentagonal), and four C(trigonal)) along the $c$ axis (inset of Fig. 1) [18]. Due to the presence of these different interstitial sites, combinations of different cations can be introduced to the structure and the properties can be tuned. The [14]structure is called 'stuffed' when all 3 interstitial sites are occupied. When all A1 and A2 sites are occupied, the structure is named 'filled' and if 5 out of 6 total A sites are occupied then it is called 'partially filled' [14] or in many other references 'unfilled' [19]. We prefer to use the 'unfilled' term in this manuscript.

Among the tetragonal bronze family, mainly strontium barium niobate $\left(\mathrm{Sr}_{x} \mathrm{Ba}_{1-x} \mathrm{Nb}_{2} \mathrm{O}_{6}\right)$, in short $\mathrm{SBN}$, has been studied for electrocaloric cooling. In SBN, C site is empty and A1 and A2 sites are not fully occupied (5 out of 6 total A sites are occupied) therefore the structure can be considered as 'unfilled'. With the increase of Sr content, SBN shows a transition from normal ferroelectric to relaxor ferroelectric state around $x=0.5$. Le Goupil et al. studied the electrocaloric effect of $\mathrm{Sr}_{0.75} \mathrm{Ba}_{0.25} \mathrm{Nb}_{2} \mathrm{O}_{6}$ single crystals, which shows relaxor ferroelectric characteristics, using direct measurements. They obtained a maximum $\Delta T$ of $\approx 0.4 \mathrm{~K}$ under $10 \mathrm{kV} / \mathrm{cm}$, when the electric field is applied along the polar direction of SBN [20]. Tang et al. [21] studied electrocaloric effect of $\mathrm{Sr}_{x} \mathrm{Ba}_{1-x} \mathrm{Nb}_{2} \mathrm{O}_{6}$ ceramics $(x=0.4,0.5$ and 0.6$)$ and re- 


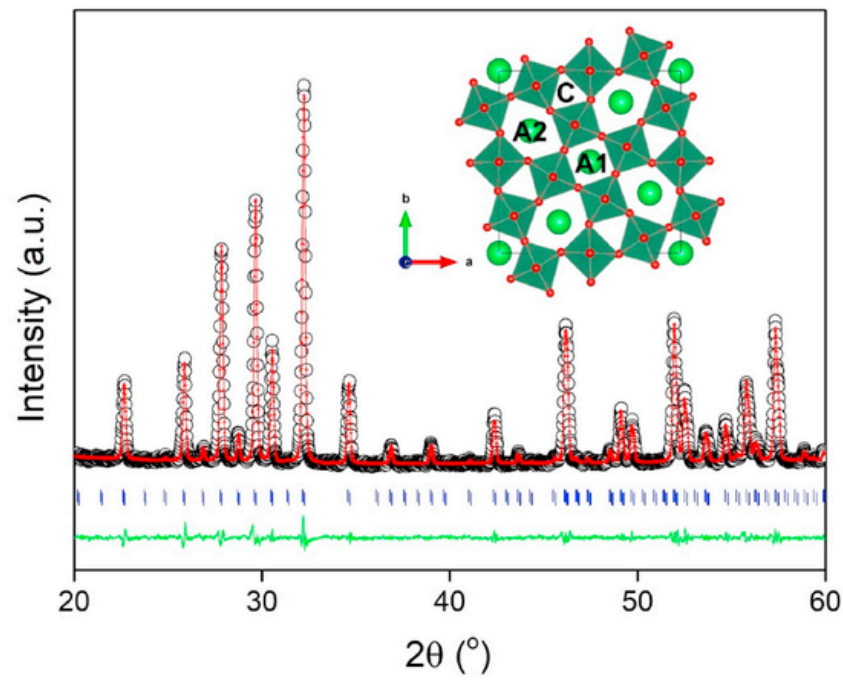

Fig. 1. Le Bail fit of the XRD spectra of dual-step sintered KNSBN. Observed XRD intensity (circles), calculated intensity (solid line), and the difference of observed and calculated patterns, $y_{\mathrm{obs}}-y_{\text {cal }}$ (solid line at the bottom). Tick marks represent the positions of allowed Bragg reflections in $P 4 \mathrm{~mm}$ space group. Inset shows the tetragonal tungsten bronze structure viewed along the $c$-axis.

ported that $\mathrm{Sr}_{0.6} \mathrm{Ba}_{0.4} \mathrm{Nb}_{2} \mathrm{O}_{6}$ has the highest $\Delta S(0.39 \mathrm{~J} / \mathrm{kg})$ and $\Delta T$ $(0.32 \mathrm{~K})$ under the $60 \mathrm{kV} / \mathrm{cm}$. They also showed that $\mathrm{Sr}_{0.6} \mathrm{Ba}_{0.4} \mathrm{Nb}_{2} \mathrm{O}_{6}$ composition has the best pyroelectric energy harvesting performance. It is reasonable to expect a material with better pyroelectric properties to show better electrocaloric properties since pyroelectric properties and electrocaloric effect are commensurate $[21,22]$. To obtain better pyroelectric properties, $\mathrm{Sr}_{x} \mathrm{Ba}_{1-x} \mathrm{Nb}_{2} \mathrm{O}_{6}$ system was doped with various cations e.g. $\mathrm{Y}^{3+}, \mathrm{La}^{3+}, \mathrm{Ce}^{3+}, \mathrm{Pr}^{3+}, \mathrm{Nd}^{3+}, \mathrm{Sm}^{3+}, \mathrm{Eu}^{3+}, \mathrm{Gd}^{3+}$, $\mathrm{Tm}^{3+}, \mathrm{Dy}^{3+}, \mathrm{Er}^{3+}, \mathrm{Yb}^{3+}, \mathrm{K}^{+}$and $\mathrm{Na}^{+}[23,24]$. Yao et al. [23] reported that pyroelectric properties of $\mathrm{Sr}_{0.5} \mathrm{Ba}_{0.5} \mathrm{Nb}_{2} \mathrm{O}_{6}$ increase with the $\mathrm{Gd}^{3+}$ dopant from $49 \mu \mathrm{C} / \mathrm{m}^{2} \mathrm{~K}$ to $168 \mu \mathrm{C} / \mathrm{m}^{2} \mathrm{~K}$ at room temperature however the origin of this improvement was not discussed. In another study, $\mathrm{Sr}_{0.6} \mathrm{Ba}_{0.4} \mathrm{Nb}_{2} \mathrm{O}_{6}$ was doped using two alkali cations $\mathrm{K}^{+}$and $\mathrm{Na}^{+}$ with the formula $\left(\mathrm{K}_{0.5} \mathrm{Na}_{0.5}\right)_{2 x}\left(\mathrm{Sr}_{0.6} \mathrm{Ba}_{0.4}\right)_{5-x} \mathrm{Nb}_{10} \mathrm{O}_{30}(0.24 \leq x \leq 1.0)$ (KNSBN) [24]. The composition with $x=0.24$ yielded the highest pyroelectric coefficient (p) of $284 \mu \mathrm{C} / \mathrm{m}^{2} \mathrm{~K}$ at room temperature and the lowest transition temperature at $130{ }^{\circ} \mathrm{C}$ among the series. This room temperature $\mathrm{p}$ is even larger than that of $\mathrm{Sr}_{0.6} \mathrm{Ba}_{0.4} \mathrm{Nb}_{2} \mathrm{O}_{6}$ ceramics. More interestingly, even though when the $\mathrm{Sr}$ content in $\mathrm{Sr}_{x} \mathrm{Ba}_{1-x} \mathrm{Nb}_{2} \mathrm{O}_{6}$ exceeds $x \geq 0.5$, a transition from normal ferroelectric to relaxor ferroelectric behavior is induced; in the case of KNSBN, it was shown that normal ferroelectric character is kept even at the lowest $\mathrm{Na}^{+}$and $\mathrm{K}^{+}$doped composition of $x=0.24$ [24] as we will discuss later.

In this study, motivated by the normal ferroelectric-like behavior and large pyroelectric coefficient reported earlier, we investigate the electrocaloric properties of $\left(\mathrm{K}_{0.5} \mathrm{Na}_{0.5}\right)_{2 x}\left(\mathrm{Sr}_{0.6} \mathrm{Ba}_{0.4}\right)_{5-x} \mathrm{Nb}_{10} \mathrm{O}_{30}$ with $x=0.24$ using the indirect method and report that in agreement with its large pyroelectric coefficient, KNSBN also shows large electrocaloric effect compared to SBN based ceramics. We use a simplified version of the chemical formula in order to compare more easily with the parent $\mathrm{Sr}_{0.6} \mathrm{Ba}_{0.4} \mathrm{Nb}_{2} \mathrm{O}_{6}$ composition: $\left(\mathrm{K}_{0.5} \mathrm{Na}_{0.5}\right)_{0.096}\left(\mathrm{Sr}_{0.6} \mathrm{Ba}_{0.4}\right)_{0.952} \mathrm{Nb}_{2} \mathrm{O}_{6}$. Dual step sintering was applied to avoid abnormal grain growth since it has been shown that in the $\mathrm{Sr}_{x} \mathrm{Ba}_{1-x} \mathrm{Nb}_{2} \mathrm{O}_{6}$ system the liquid phase can easily form during the sintering process which might cause abnormal grain growth [25-27]. It is known that abnormal grain growth might result in deterioration of the dielectric and ferroelectric properties $[26,28]$. While we focus on the electrocaloric properties of the sample obtained by dual-step sintering, we also provide a comparison of the microstructure, dielectric and ferroelectric properties of this sample with the sample obtained using conventional sintering.

\section{Experimental}

KNSBN was prepared from $\mathrm{K}_{2} \mathrm{CO}_{3}(\geq 99.0 \%$, Isolab Chemicals), $\mathrm{Na}_{2} \mathrm{CO}_{3}$ ( $\geq 99.8 \%$, Isolab Chemicals), $\mathrm{SrCO}_{3}$ ( $\geq 99.5 \%$, Enteknomaterials), $\mathrm{BaCO}_{3}$ ( $\geq 99.5 \%$, Enteknomaterials), and $\mathrm{Nb}_{2} \mathrm{O}_{5}$ ( $\geq 99.5 \%$, Alfa Aesar). Starting powders were mixed in ethanol using planetary ball milling (Retsch PM 100) in a nalgene bottle with zirconia balls for $18 \mathrm{~h}$. The mixed powder was dried and calcined at $1100{ }^{\circ} \mathrm{C}$ for $6 \mathrm{~h}$. The calcined powder was mixed with $5 \mathrm{wt} \%$ polyvinyl alcohol as the binder and formed into the pellets using uniaxial pressing. Binder burnout was performed at $600{ }^{\circ} \mathrm{C}$ for $5 \mathrm{~h}$ with a heating rate of $1{ }^{\circ} \mathrm{C} / \mathrm{min}$. For the dual-step sintered sample, first pre-sintering was carried out at $1150{ }^{\circ} \mathrm{C}$ for $4 \mathrm{~h}$ with a heating rate of $5{ }^{\circ} \mathrm{C} / \mathrm{min}$. Then, the sample was again sintered at $1270{ }^{\circ} \mathrm{C}$ for $2 \mathrm{~h}$ with a heating rate of $5{ }^{\circ} \mathrm{C} / \mathrm{min}$. Pre-sintering step was not applied for the conventionally sintered sample i.e. after binder burnout the sample was directly sintered at $1270{ }^{\circ} \mathrm{C}$ for $2 \mathrm{~h}$ with a heating rate of $5{ }^{\circ} \mathrm{C} / \mathrm{min}$. The density of pellets were measured using the Archimedes method. Phase analysis of samples was done by X-ray diffraction (Panalytical X'Pert Pro) and unit cell parameters were obtained from Le Bail fits using Rietica [29]. Polishing and thermal etching were applied for microstructural observation. The morphology of the sample was analyzed by a scanning electron microscope (SEM, Quanta 250 FEG). The average grain size was calculated using the linear intercept method.

For the electrical measurements, both sides of the pellet were coated with silver epoxy. The dielectric constant of the sample was measured using an LCR-meter (Keysight E4980AL) between 50 and $200{ }^{\circ} \mathrm{C}$ at $100 \mathrm{~Hz}, 1 \mathrm{kHz}, 10 \mathrm{kHz}$ and $100 \mathrm{kHz}$. Ferroelectric hysteresis loops were measured using a commercial ferroelectric tester (Aixacct TF Analyzer 1000) at $10 \mathrm{~Hz}$ between room temperature and $160{ }^{\circ} \mathrm{C}$.

Electrocaloric temperature change $(\Delta \mathrm{T})$ of the sample was calculated using the indirect method based on Maxwell's equations (Eq. (1)).

$\Delta T=-\frac{1}{\rho} \int_{E_{1}}^{E_{2}} \frac{T}{c}\left(\frac{\partial P}{\partial T}\right)_{E} d E$

where $P$ is the electrical polarization, E1, E2 are initial and final electric field, $c$ is the heat capacity, $\rho$ is the density and $T$ is the temperature.

\section{Results and discussion}

\subsection{Structural characterization}

Le Bail fit to the X-ray diffraction spectra of dual-step sintered KNSBN is shown in Fig. 1. All observed peaks belong to the tetragonal tungsten bronze structure. Lattice parameters were obtained from the Le Bail fit using the tetragonal tungsten bronze structure of SBN with the space group $P 4 \mathrm{~mm}$ as the standard [30]. The fit quality was good, evidenced by the difference curve and the low $R_{w p}$ of $4.44 \%$. Lattice parameters $a$ and $c$ were obtained as 12.449(6) $\AA$ and 3.933(9) $\AA$, respectively, in agreement with KNSBN compositions reported in Refs. [24].

Fig. 2 shows SEM micrograph of the surface of the sample sintered using dual step sintering. While the abnormal grain growth could be prevented: i.e. giant grains of $100 \mu \mathrm{m}$ size were not observed [27], grain size distribution is broad and not homogeneous. Similar microstructure was reported for some SBN compositions synthesized using dual sintering [31]. The average grain size was estimated to be $\sim 2 \mu \mathrm{m}$ (Fig. 2 ). The measured density of the sample was $\sim 91 \%$ of the theoretical density. We note that following conventional sintering with the same calcination temperature and the single sintering step at $1270{ }^{\circ} \mathrm{C}$ for $2 \mathrm{~h}$, we have obtained a microstructure (Fig.S2(b)) with cracks and inhomogeneities, suggesting liquid phase formation and abnormal grain growth. Adding a pre-sintering step (i.e. dual-step sintering) approximately $100{ }^{\circ} \mathrm{C}$ below the normal sintering temperature 


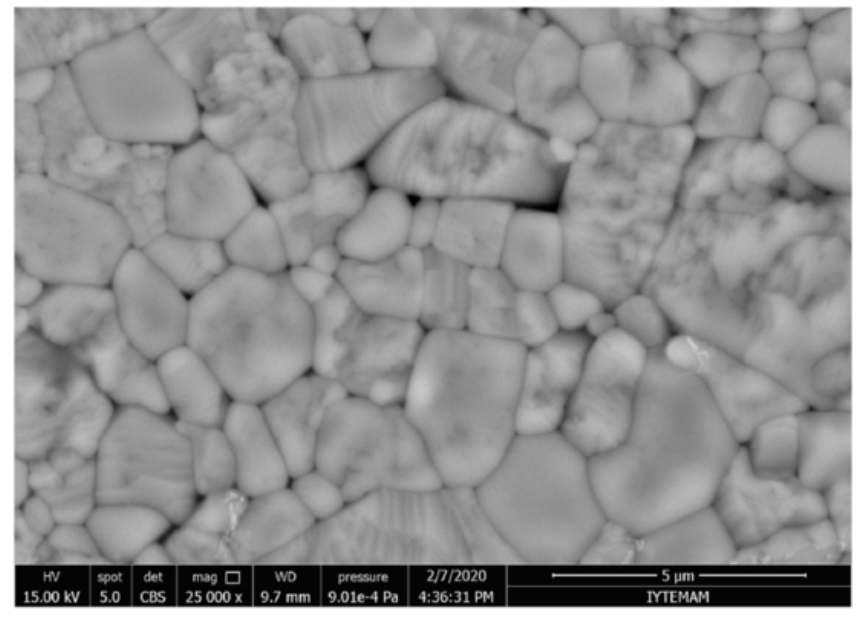

Fig. 2. SEM surface micrograph of dual-step sintered KNSBN.

is reported to prevent liquid phase formation since the liquid phase formation is triggered by incomplete calcination [27]. Comparison of the sintering profiles and microstructures of the two samples obtained using conventional and dual-step sintering is provided in the supplementary material (Fig. S1 and S2).

\subsection{Dielectric properties}

Dielectric constant $(\varepsilon)$ and dielectric loss $(\tan \delta)$ of dual-step sintered KNSBN in the temperature range of $50-200{ }^{\circ} \mathrm{C}$ and at various frequencies $(100 \mathrm{~Hz}, 1 \mathrm{kHz}, 10 \mathrm{kHz}$, and $100 \mathrm{kHz})$ are presented in Fig. 3. Dielectric constant shows a broad peak at the transition temperature (Tm) around $111{ }^{\circ} \mathrm{C}$. In agreement with the study of Yao et al. [24], dielectric peak position does not shift significantly towards higher temperatures with increasing frequency, pointing to a normal ferroelectric with diffuse phase transition character rather than a ferroelectric relaxor. This is in contrast to what has been reported for $\mathrm{Sr}_{0.6} \mathrm{Ba}_{0.4} \mathrm{Nb}_{2} \mathrm{O}_{6}$ ceramics, where a clear shift in the broad dielectric maximum to higher temperatures is reported [32,33]. The maximum value of our dielectric constant is smaller than that reported in Ref. [24]. This could be due to the slightly smaller average grain size of our samples $(2 \mu \mathrm{m}$ compared to $5 \mu \mathrm{m})$. It is well known that the larger grain size can yield better dielectric and ferroelectric properties $[27,34]$. $\mathrm{T}_{\mathrm{m}}$ we obtained is also lower than that reported in the earlier report [24]. This lower transition temperature might have resulted from the slightly lower grain

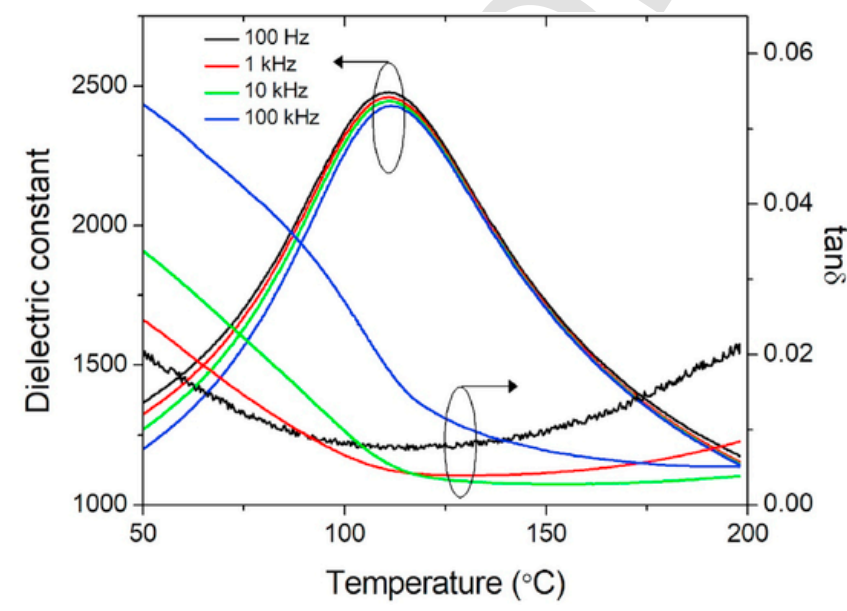

Fig. 3. Temperature dependence of dielectric constant and dielectric loss of dual-step sintered KNSBN at different frequencies. size of our samples. It was reported that Ce doping suppresses grain growth in $\mathrm{Sr}_{0.5} \mathrm{Ba}_{0.5} \mathrm{Nb}_{2} \mathrm{O}_{6}$ ceramics and in turn causes a significant decrease in Curie temperature due to the larger internal stress in fine grained samples [35]. The dielectric loss of the sample decreased with increasing temperature until the temperature of the dielectric maximum and then reaches a plateau for 10 and $100 \mathrm{kHz}$. The temperature of the plateau shifts to higher temperatures with increasing frequency. At $100 \mathrm{~Hz}$ and $1 \mathrm{kHz}$, an increase of dielectric loss at high temperatures was observed which might be related to the increasing dc conductivity at these temperatures [36]. Dielectric loss was smaller than 0.022 over the whole temperature range. Comparison of the temperature dependence of the dielectric constant of the samples obtained using conventional and dual-step sintering is provided in Fig. S3. Dielectric constant of the dual-step sintered sample is larger than that of the conventionally sintered one, while its dielectric maximum temperature is lower. Similar behaviour was reported for SBN ceramics and explained in terms of the internal stress developed in fine-grained samples (obtained by dual-step sintering) during cooling [27].

As mentioned in the introduction section, in the SBN system, $\mathrm{Sr}^{2+}$ and $\mathrm{Ba}^{2+}$ occupy $\mathrm{A} 1$ and $\mathrm{A} 2$ sites while $\mathrm{C}$ site of TTB structure is empty. Five of the six A-site positions are occupied: A1 sites are filled by $\mathrm{Sr}^{2+}$ ions, whereas both $\mathrm{Sr}^{2+}$ and $\mathrm{Ba}^{2+}$ can occupy $\mathrm{A} 2$ site. There is a strong correlation between the occupancy of the A1 and A2 sites and the relaxor ferroelectric character of the material. Normal ferroelectric behavior with no frequency dispersion of the dielectric peak was observed for $\mathrm{Sr}_{x} \mathrm{Ba}_{1-x} \mathrm{Nb}_{2} \mathrm{O}_{6}$ when $x=0.20(\mathrm{Sr} / \mathrm{Ba}=1 / 4)$. In that case, four A2 sites are occupied by $\mathrm{Ba}^{2+}$ while one of the two $\mathrm{A} 1$ sites is occupied by one $\mathrm{Sr}^{2+}$ and thus, an ordered and even distribution of ions is obtained [19]. When the composition moves away from $x=0.25$, cation distribution becomes disordered and relaxor ferroelectric behavior is observed with the signature of frequency dispersion of the dielectric maximum. The strength of frequency dispersion in $\mathrm{Sr}_{x} \mathrm{Ba}_{1-x} \mathrm{Nb}_{2} \mathrm{O}_{6}$ system increases with strontium content $[19,37]$. It has been established that the origin of the relaxor behavior in SBN is the 'quenched electric random fields related to randomly distributed vacancies on the A-sites' [38]. One way to decrease the disorder and frequency dispersion is introducing alkali ions such as $\mathrm{Na}^{+}$and $\mathrm{K}^{+}$. Introduction of $\mathrm{Na}^{+}$and $\mathrm{K}^{+}$to the structure causes the filling of vacant $\mathrm{A} 1$ and $\mathrm{A} 2$ sites since for each divalent cation, two monovalent $\mathrm{Na}^{+}$or $\mathrm{K}^{+}$are introduced while small C sites remain unoccupied $[33,39]$. This decrease in the vacant sites is reported to cause the suppression of relaxor ferroelectric properties and induces diffuse phase transition [33]. In our case, the amount of $\mathrm{Na}^{+}$or $\mathrm{K}^{+}$introduced at the A-sites is quite small however is enough to decrease the frequency dispersion and induce normal ferroelectric behavior with diffuse phase transition character.

\subsection{Ferroelectric and electrocaloric properties}

In Fig. 4 ferroelectric hysteresis loops of dual-step sintered KNSBN measured at $10 \mathrm{~Hz}$ and different temperatures are shown. At room temperature, the sample exhibits a typical hysteresis loop. Hysteresis loops become slimmer with increasing temperature and at and above $\mathrm{T}_{\mathrm{m}}=111^{\circ} \mathrm{C}$, they fully close-up and at the highest measurement temperature of $160{ }^{\circ} \mathrm{C}$ an almost linear loop is observed, suggesting that the paraelectric state is reached. The value of the maximum polarization is comparable to SBN ceramics [40] when compared to the same electric field. A comparison of the hysteresis loops of the samples obtained using conventional and dual-step sintering is provided in Fig. S4. It can be observed that while the maximum polarization of the dual-step sintered sample is larger, its coercive is smaller than that of the conventionally sintered sample. These differences are related to the higher density (91 vs. $86 \%$ ), better crystallinity and relatively homogeneous microstructure of the dual-step sintered sample. 


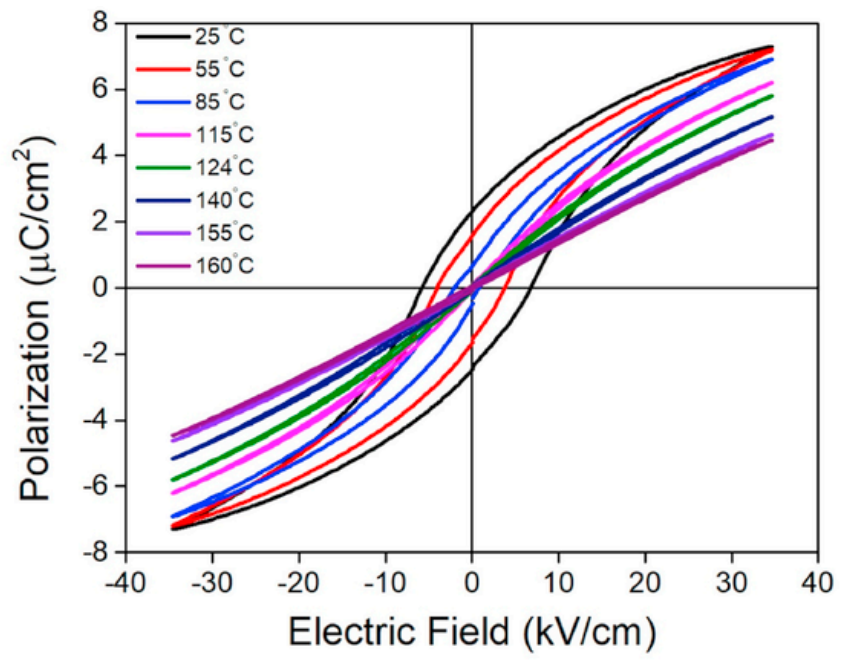

Fig. 4. Ferroelectric hysteresis loops of dual-step sintered KNSBN at different temperatures measured at $10 \mathrm{~Hz}$.

Electrocaloric temperature change $(\Delta \mathrm{T})$ of the dual-step sintered sample was calculated by the indirect method, using equation (1). For the calculation, first $\left(\frac{\partial P}{\partial T}\right)_{E}$ was obtained. In order to do this, the temperature dependence of the electrical polarization at different electric fields were plotted using the data from the upper branches of the hysteresis loops, as illustrated in Fig. 5(a). The curves were fitted with 6th order polynomials and then the fitted curve is differentiated. $\Delta T$ was then calculated using equation (1). In the calculation, measured density $(\rho)$ of $4.81 \mathrm{~g} / \mathrm{cm}^{3}$ was used. Heat capacity (c) value of $330 \mathrm{~J} / \mathrm{kgK}$ was taken from Ref. [24] which is the value reported for the KNSBN

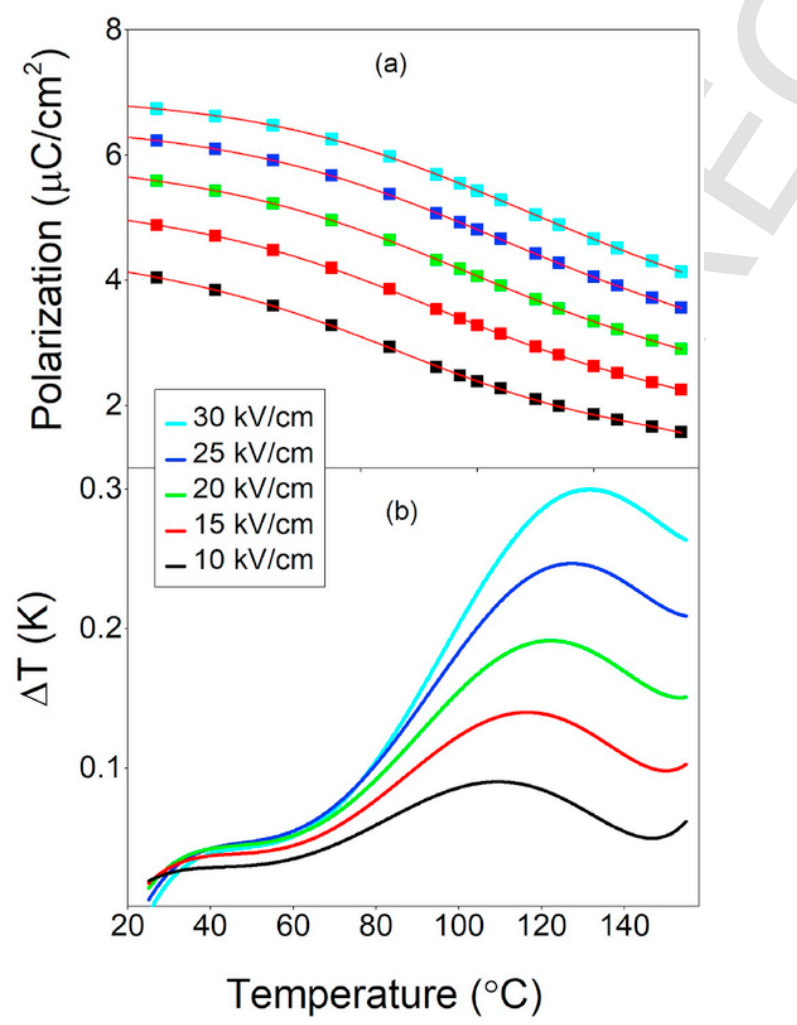

Fig. 5. (a) Electrical polarization of dual-step sintered KNSBN as a function of temperature at different electric fields. The solid line is a fit to a sixth-degree polynomial, (b) Electrocaloric temperature change $(\Delta \mathrm{T})$ of dual-step sintered KNSBN as a function of temperature at different electric fields. of the same composition. The temperature evolution of $\Delta T$ under different electric fields is shown in Fig. 5(b). $\Delta T$ shows a broad peak at around $\mathrm{T}_{\mathrm{m}}=111{ }^{\circ} \mathrm{C}$ under $10 \mathrm{kV} / \mathrm{cm} \Delta T$ peak shifts to higher temperatures as the electric field is increased. $\Delta T$ reaches $0.3 \mathrm{~K}$ under $30 \mathrm{kV} /$ $\mathrm{cm}$ at around $133{ }^{\circ} \mathrm{C}$ and the calculated electrocaloric responsivity or strength $(\Delta T / \Delta E)$ is $0.1 \mathrm{~K} * \mathrm{~mm} / \mathrm{kV}$ at this temperature. Even though this value is modest among Pb-free ceramics, it is the largest among SBN based ceramics as we discuss below. We note that the dual-step sintered sample underwent dielectric breakdown above $30 \mathrm{kV} / \mathrm{cm}$. This relatively low dielectric breakdown strength is likely to originate from the slightly low density of the sample since density is one of the key factors controlling the breakdown strength [41]. Conventionally sintered sample had even lower breakdown strength as it underwent dielectric breakdown at high temperatures. Therefore its electrocaloric property measurements couldn't be completed. This must be caused by its inhomogenous microstructure.

In Table 1, the electrocaloric properties of KNSBN are compared with different SBN compositions in ceramic and single crystal form. In order to compare the electrocaloric effect, $\Delta T / \Delta E$ values for each material are listed. In addition to the measurement method, the nature of the material i.e. whether the material behaves as a ferroelectric relaxor or normal ferroelectric is also included in the table. KNSBN shows better electrocaloric responsivity than all SBN ceramic compositions reported so far however as expected single crystal SBN compositions outplay KNSBN ceramic. We stress that all SBN compositions listed in Table 1 are mostly relaxor ferroelectrics unlike the KNSBN composition we report here. Indirect measurement of electrocaloric effect based on Maxwell's relations is not accurate for relaxor ferroelectrics nevertheless it is still used to estimate the electrocaloric effect. Direct measurement was shown to yield larger electrocaloric temperature change for many ceramics compared to the indirect method [42-44]. Large $\Delta T$ of KNSBN is in accordance with its large room temperature pyroelectric coefficient $(p)$ reported by Yao et al. $\left(284 \mu \mathrm{C} / \mathrm{m}^{2} \mathrm{~K}\right)$. KNSBN's room temperature pyroelectric coefficient is greater than that of $\mathrm{Sr}_{0.5} \mathrm{Ba}_{0.5} \mathrm{Nb}_{2} \mathrm{O}_{6}$ ceramics $\left(200 \mu \mathrm{C} / \mathrm{m}^{2} \mathrm{~K}\right)$ [17], which has the largest $p$ among SBN compositions. And this difference does not originate from a proximity effect to the Curie temperature. $\mathrm{Sr}_{0.5} \mathrm{Ba}_{0.5} \mathrm{Nb}_{2} \mathrm{O}_{6}$ ceramics has a $\mathrm{T}_{\mathrm{C}}$ of around $80^{\circ} \mathrm{C}$ [17] which is lower than KNSBN. This difference between $\mathrm{p}$ of KNSBN and SBN ceramics points out to a sharper change of electrical polarization in KNSBN and partially accounts for the large $\Delta T$ obtained in this study. The difference in $\Delta T$ between single crystals and ceramics can be anticipated by looking at the large value of $\mathrm{p}$ of $\mathrm{Sr}_{0.5} \mathrm{Ba}_{0.5} \mathrm{Nb}_{2} \mathrm{O}_{6}$ single crystal: $550 \mu \mathrm{C} / \mathrm{m}^{2} \mathrm{~K}$ [45]. SBN has strongly anisotropic electrical properties and is polar only along [001] direction. In ceramics, randomly oriented grains result in an average value of all directions which causes a decrease in pyroelectric coefficient.

We suggest that the origin of the electrocaloric effect and the large pyroelectric coefficient in KNSBN must be related to the stabilization of ferroelectricity upon $\mathrm{K}^{+}$and $\mathrm{Na}^{+}$co-substitution. It has been reported that remanent polarization increases as the amount of $\mathrm{K}^{+}$and $\mathrm{Na}^{+}$increases in KNSBN ceramics [24], which is an indication of the stabilization of ferroelectricity upon doping. In our case, we also observe a relatively large remanent polarization, an increase in the Curie temperature compared to undoped $\mathrm{Sr}_{0.6} \mathrm{Ba}_{0.4} \mathrm{Nb}_{2} \mathrm{O}_{6}$ as well as dissappearance of the shift of dielectric maximum with increasing frequency; all of which support the stabilization of the ferroelectricity. A similar increase of remanent polarization was observed in $\mathrm{Ca}_{x} \mathrm{Sr}_{0.3-\mathrm{x}} \mathrm{Ba}_{0.7} \mathrm{Nb}_{2} \mathrm{O}_{6}$ ceramics where $\mathrm{Ca}^{2+}$ doping was suggested to stabilize the ferroelectricity of the material, evidenced by an increase in Curie temperature and remanent polarization with the doping. In addition, the pyroelectric coefficient also increased with increasing $\mathrm{Ca}^{2+}$ content [46]. Based on these reports and the observation of normal ferroelectric behavior in our KNSBN, we suggest the relatively large electrocaloric responsivity we measure on KNSBN as well as the previously reported large pyroelec- 
Table 1

Comparison of electrocaloric properties for different SBN related materials.

\begin{tabular}{|c|c|c|c|c|c|c|c|}
\hline Material & Form & $\operatorname{Tc}$ or $\operatorname{Tm}\left({ }^{\circ} \mathrm{C}\right)$ & $\Delta \mathrm{T}(\mathrm{K})$ & $\mathrm{E}(\mathrm{kV} / \mathrm{cm})$ & $\Delta \mathrm{T} / \Delta \mathrm{E}(\mathrm{K} * \mathrm{~mm} / \mathrm{kV})$ & Method/Material Type & Ref. \\
\hline $\mathrm{Sr}_{0.5} \mathrm{Ba}_{0.5} \mathrm{Nb}_{2} \mathrm{O}_{6}$ & ceramic & 50 & 0.35 & 100 & 0.035 & indirect/relaxor & [47] \\
\hline $\mathrm{Sr}_{0.6} \mathrm{Ba}_{0.4} \mathrm{Nb}_{2} \mathrm{O}_{6}$ & ceramic & 134 & 0.32 & 60 & 0.053 & indirect/relaxor & [21] \\
\hline $\mathrm{Sr}_{0.698} \mathrm{Gd}_{0.002} \mathrm{Ba}_{0.3} \mathrm{Nb}_{2} \mathrm{O}_{6}$ & ceramic & 40 & 0.085 & 15 & 0.056 & indirect/relaxor & [48] \\
\hline $\mathrm{Sr}_{0.6} \mathrm{Ba}_{0.4} \mathrm{Nb}_{2} \mathrm{O}_{6}$ & Single crystal & $<35$ & 0.42 & 10 & 0.42 & direct/relaxor & [20] \\
\hline $\mathrm{Sr}_{0.61} \mathrm{Ba}_{0.39} \mathrm{Nb}_{2} \mathrm{O}_{6}+1.4 \% \mathrm{Ce}$ & Single crystal & $<30$ & 0.85 & 28 & 0.303 & direct/relaxor & [49] \\
\hline KNSBN & ceramic & 133 & 0.30 & 30 & 0.1 & indirect/normal ferroelectric & This work \\
\hline
\end{tabular}

tric coefficient, must be related to the stabilization of ferroelectricity with doping. To better understand the origin of large $p$ and electrocaloric responsivity of KNSBN ceramics, however, more work on the possible correlation between the filling of A-site positions with $\mathrm{K}^{+}$ and $\mathrm{Na}^{+}$and the increase in the pyroelectric coefficient and preferably direct measurement of the electrocaloric effect to compare the electrocaloric temperature change of SBN and KNSBN, are necessary.

\section{Conclusions}

We have investigated the electrocaloric properties of $\mathrm{K}^{+}$and $\mathrm{Na}^{+}$ co-doped SBN. Despite the low amount of alkali doping, KNSBN showed normal ferroelectric like behavior with no significant shift of dielectric maximum temperature with increasing frequency. KNSBN shows a maximum $\Delta T$ of $0.3 \mathrm{~K}$ under $30 \mathrm{kV} / \mathrm{cm}$ which corresponds to an electrocaloric responsivity of $0.1 \mathrm{~K} * \mathrm{~mm} / \mathrm{kV}$ around $130{ }^{\circ} \mathrm{C}$. This value is larger than those of SBN ceramics and is in agreement with the larger pyroelectric coefficient value of KNSBN compared to SBN ceramics. We suggest that the relatively large $\Delta T$ and $p$ originates from the stabilization of ferroelectricity upon doping.

\section{CRediT authorship contribution statement}

Arif Kurnia: Data curation, Writing - original draft. Emriadi: Writing - review \& editing. Nandang Mufti: Supervision, Writing - review \& editing. Zulhadjri: Supervision, Writing - review \& editing. Umut Adem: Conceptualization, Supervision, Writing - review \& editing.

\section{Declaration of competing interest}

The authors declare that they have no known competing financial interests or personal relationships that could have appeared to influence the work reported in this paper.

\section{Acknowledgments}

This work was supported by the Ministry of Research, Technology and Higher Education of the Republic of Indonesia through the PMDSU Scholarship (Grant number 050/SP2H/LT/DRPM/2018) and the PKPI-PMDSU Scholarship (Grant number 1406.53/D3/PG/2018). The authors thank İzmir Institute of Technology's Center for Materials Research for XRD and SEM experiments. One of the authors (AK) thanks Merve Karakaya, Meriç Güvenç and Melike Tokkan for their help with the experiments and fruitful discussions.

\section{Appendix A. Supplementary data}

Supplementary data to this article can be found online at https://doi. org/10.1016/j.jallcom.2020.156132.

\section{References}

[1] S-G Lu, Q Zhang, Electrocaloric materials for solid-state refrigeration, Adv. Mater. 21 (2009) 1983-1987, doi:10.1002/adma.200802902.

[2] L Luo, X Jiang, Y Zhang, K Li, Electrocaloric effect and pyroelectric energy harvesting of $(0.94-\mathrm{x}) \mathrm{Na}_{0.5} \mathrm{Bi}_{0.5} \mathrm{TiO}_{3}-0.06 \mathrm{BaTiO}_{3}$ - $\mathrm{SSrTiO}_{3}$ ceramics, J. Eur. Ceram. Soc. 37 (2017) 2803-2812, doi:10.1016/j.jeurceramsoc.2017.02.047.
[3] A S Mischenko, Q Zhang, J F Scott, R W Whatmore, N D Mathur, Giant electrocaloric effect in thin-film $\mathrm{PbZr}_{0.95} \mathrm{Ti}_{0.05} \mathrm{O}_{3}$, Science 311 (2006) 1270-1271, doi:10.1126/science.1123811.

[4] K S Srikanth, R Vaish, Enhanced electrocaloric, pyroelectric and energy storage performance of $\mathrm{BaCe}_{\mathrm{x}} \mathrm{Ti}_{1-\mathrm{x}} \mathrm{O}_{3}$ ceramics, J. Eur. Ceram. Soc. 37 (2017) 3927-3933, doi:10.1016/j.jeurceramsoc.2017.04.058.

[5] M Valant, Electrocaloric materials for future solid-state refrigeration technologies, Prog. Mater. Sci. 57 (2012) 980-1009, doi:10.1016/ j.pmatsci.2012.02.001.

[6] J Li, D Zhang, S Qin, T Li, M Wu, D Wang, Y Bai, X Lou, Large room-temperature electrocaloric effect in lead-free $\mathrm{BaHf}_{\mathrm{x}} \mathrm{Ti}_{1-\mathrm{x}} \mathrm{O}_{3}$ ceramics under low electric field, Acta Mater. 115 (2016) 58-67, doi:10.1016/ j.actamat.2016.05.044.

[7] M Wu, D S Song, G Vats, S C Ning, M Y Guo, D W Zhang, D Q Xue, S J Pennycook, X J Lou, Defect-controlled electrocaloric effect in $\mathrm{PbZrO}_{3}$ thin films, J. Mater. Chem. C. 6 (2018) 10332-10340, doi:10.1039/c8tc03965h.

[8] M Marathe, D Renggli, M Sanlialp, M O Karabasov, V V Shvartsman, D C Lupascu, A Grünebohm, C Ederer, Electrocaloric effect in $\mathrm{BaTiO}_{3}$ at all three ferroelectric transitions: anisotropy and inverse caloric effects, Phys. Rev. B 96 (2017), doi:10.1103/PhysRevB.96.014102 014102.

[9] R Kumar, S Singh, Enhanced electrocaloric response and high energy-storage properties in lead-free $(1-\mathrm{x})\left(\mathrm{K}_{0.5}\right) \mathrm{NbO}_{3}-\mathrm{xSrZrO}_{3}$ nanocrystalline ceramics, $\mathrm{J}$. Alloys Compd. 764 (2018) 289-294, doi:10.1016/j.jallcom.2018.06.083.

[10] Z D Luo, D W Zhang, Y Liu, D Zhou, Y G Yao, C Q Liu, B Dkhil, X B Ren, X J Lou, Enhanced electrocaloric effect in lead-free $\mathrm{BaTi}_{1-\mathrm{x}} \mathrm{Sn}_{\mathrm{x}} \mathrm{O}_{3}$ ceramics near room temperature, Appl. Phys. Lett. 105 (2014) 102904, doi:10.1063/ 1.4895615 .

[11] K Şanll, U Adem, Electrocaloric properties of $\mathrm{Ba}_{0.8} \mathrm{Sr}_{0.2} \mathrm{Ti}_{1-\mathrm{x}} \mathrm{Zr}_{\mathrm{x}} \mathrm{O}_{3}(0 \leq \mathrm{x} \leq 0.1)$ system: the balance between the nature of the phase transition and phase coexistence, Ceram. Int. 46 (2020) 2213-2219, doi:10.1016/ j.ceramint.2019.09.206.

[12] W P Cao, W L Li, D Xu, Y F Hou, W Wang, W D Fei, Enhanced electrocaloric effect in lead-free NBT-based ceramics, Ceram. Int. 40 (2014) 9273-9278, doi:10.1016/j.ceramint.2014.01.149.

[13] J Koruza, B Rozic, G Cordoyiannis, B Malic, Z Kutnjak, Large electrocaloric effect in lead-free $\mathrm{K}_{0.5} \mathrm{Na}_{0.5} \mathrm{NbO}_{3}-\mathrm{SrTiO}_{3}$ ceramics, Appl. Phys. Lett. 106 (2015) 4, doi:10.1063/1.4921744.

[14] J R Oliver, R R Neurgaonkar, L E Cross, Ferroelectric properties of tungsten bronze morphotropic phase bounary systems, J. Am. Ceram. Soc. 72 (1989) 202-211, doi:10.1111/j.1151-2916.1989.tb06102.x.

[15] R R Neurgaonkar, W K Cory, Progress in photorefractive tungsten bronze crystals, J. Opt. Soc. Am. B 3 (1986) 274-282, doi:10.1364/JOSAB.3.000274.

[16] B Yang, L Wei, X Chao, Z Wang, Z Yang, Role of structural modulation in electrical properties of tungsten bronze $\left(\mathrm{Ca}_{0.28} \mathrm{Ba}_{0.72}\right)_{2.5-0.5 \mathrm{x}} \mathrm{Na}_{\mathrm{x}} \mathrm{Nb}_{5} \mathrm{O}_{15}$ ceramics, J. Alloys Compd. 632 (2015) 368-375, doi:10.1016/ j.jallcom.2015.01.247.

[17] J Zhang, G Wang, F Gao, C Mao, F Cao, X Dong, Influence of Sr/Ba ratio on the dielectric, ferroelectric and pyroelectric properties of strontium barium niobate ceramics, Ceram. Int. 39 (2013) 1971-1976, doi:10.1016/ j.ceramint.2012.08.048.

[18] M Aftabuzzaman, M A Helal, R Paszkowski, J Dec, W Kleemann, S Kojima, Electric field and aging effects of uniaxial ferroelectrics $\mathrm{Sr}_{\mathrm{x}} \mathrm{Ba}_{1-\mathrm{x}} \mathrm{Nb}_{2} \mathrm{O}_{6}$ probed by Brillouin scattering, Sci. Rep. 7 (2017) 11615, doi:10.1038/ s41598-017-10985-9.

[19] C J Huang, K Li, X Q Liu, X L Zhu, X M Chen, Effects of A1/A2-sites occupancy upon ferroelectric transition in $\left(\mathrm{Sr}_{\mathrm{x}} \mathrm{Ba}_{1-\mathrm{x}}\right) \mathrm{Nb}_{2} \mathrm{O}_{6}$ tungsten bronze ceramics, $\mathrm{J}$. Am. Ceram. Soc. 97 (2014) 507-512, doi:10.1111/jace.12659.

[20] F Le Goupil, A K Axelsson, L J Dunne, M Valant, G Manos, T Lukasiewicz, J Dec, A Berenov, N M N Alford, Anisotropy of the electrocaloric effect in lead-free relaxor ferroelectrics, Adv. Energy Mater. 4 (2014) 1301688, doi:10.1002/aenm.201301688.

[21] H Tang, X-G Tang, M-D Li, Q-X Liu, Y-P Jiang, Pyroelectric energy harvesting capabilities and electrocaloric effect in lead-free $\mathrm{Sr}_{\mathrm{x}} \mathrm{Ba}_{1-\mathrm{x}} \mathrm{Nb}_{2} \mathrm{O}_{6}$ ferroelectric ceramics, J. Alloys Compd. 791 (2019) 1038-1045, doi:10.1016/ j.jallcom.2019.03.385.

[22] S Zeng, X Tang, Q Liu, Y Jiang, M Li, W Li, Z Tang, Electrocaloric effect and pyroelectric properties in Ce-doped $\mathrm{BaCe}_{\mathrm{x}} \mathrm{Ti}_{1-\mathrm{x}} \mathrm{O}_{3}$ ceramics, J. Alloys Compd. 776 (2018) 731-739, doi:10.1016/j.jallcom.2018.10.293.

[23] Y Yao, C L Mak, K H Wong, S Lu, Z Xu, Effects of rare-earth dopants on the ferroelectric and pyroelectric properties of Strontium Barium Niobate Ceramics, Int. J. Appl. Ceram. Technol. 6 (2009) 671-678, doi:10.1111/ j.1744-7402.2008.02308.x. 
[24] Y B Yao, C L Mak, B Ploss, Phase transitions and electrical characterizations of $\left(\mathrm{K}_{0.5} \mathrm{Na}_{0.5}\right)_{2 \mathrm{x}}\left(\mathrm{Sr}_{0.6} \mathrm{Ba}_{0.4}\right)_{5-\mathrm{x}} \mathrm{Nb}_{10} \mathrm{O}_{30}$ (KNSBN) ceramics with "unfilled" and " filled ' tetragonal tungsten - bronze ( TTB ) crystal structure, J. Eur. Ceram. Soc. 32 (2012) 4353-4361, doi:10.1016/j.jeurceramsoc.2012.07.034.

[25] T-T Fang, E Chen, W-J Lee, On the discontinuous grain growth of $\mathrm{Sr}_{\mathrm{x}} \mathrm{Ba}_{1-\mathrm{x}} \mathrm{Nb}_{2} \mathrm{O}_{6}$ ceramics, J. Eur. Ceram. Soc. 20 (2000) 527-530, doi:10.1016/ s0955-2219(99)00178-8.

[26] $\mathrm{H}$ Lee, $\mathrm{R}$ Freer, Abnormal grain growth and liquid-phase sintering in $\mathrm{Sr}_{0.6} \mathrm{Ba}_{0.4} \mathrm{Nb}_{2} \mathrm{O}_{6}$ (SBN40) ceramics, J. Mater. Sci. 33 (1998) 1703-1708, doi:10.1023/A:1004312128588.

[27] $\mathrm{H}$ Y Lee, $\mathrm{R}$ Freer, The mechanism of abnormal grain growth in $\mathrm{Sr}_{0.6} \mathrm{Ba}_{0.4} \mathrm{Nb}_{2} \mathrm{O}_{6}$ ceramics, J. Appl. Phys. 81 (1997) 376-382, doi:10.1063/1.364122.

[28] J Li, Y Pu, Z Wang, J Dai, A comparative study of $\mathrm{Sr}_{0.7} \mathrm{Ba}_{0.3} \mathrm{Nb}_{2} \mathrm{O}_{6}$ relaxor ferroelectric ceramics prepared by conventional and microwave sintering techniques, Ceram. Int. 39 (2013) 5069-5075, doi:10.1016/ j.ceramint.2012.12.001.

[29] J C Howard, B A Hunter, B A Rietica, A computer program for Rietvield analysis of X-ray and neutron powder diffarction pattern, Lucas Height, Res. Lab. 1 (1998) 27, doi:10.3938/jkps.66.1077.

[30] S Podlozhenov, H A Graetsch, J Schneider, M Ulex, M Wöhlecke, K Betzler, Structure of strontium barium niobate $\mathrm{Sr}_{\mathrm{x}} \mathrm{Ba}_{1-\mathrm{x}} \mathrm{Nb}_{2} \mathrm{O}_{6}(\mathrm{SBN})$ in the composition range $0.32 \leq \mathrm{x} \leq 0.82$, Acta Crystallogr. Sect. B Struct. Sci. B62 (2006) 960-965, doi:10.1107/S0108768106038869.

[31] M S Kim, J H Lee, J J Kim, H Y Lee, S H Cho, Origin of abnormal grain growth in tungsten bronze structured ferroelectric $\mathrm{Sr}_{\mathrm{x}} \mathrm{Ba}_{1-\mathrm{x}} \mathrm{Nb}_{2} \mathrm{O}_{6}$ ceramics, Japanese $\mathrm{J}$. Appl. Physics, Part 1 Regul. Pap. Short Notes Rev. Pap. 41 (2002) 7048-7052, doi:10.1143/JJAP.41.7048.

[32] Y Zhao, J Wang, L Zhang, X Shi, S Liu, D Zhang, Relaxor transition and properties of Mn-doped $\mathrm{Sr}_{\mathrm{x}} \mathrm{Ba}_{1-\mathrm{x}} \mathrm{Nb}_{2} \mathrm{O}_{6}$ ferroelectric ceramics, Ceram. Int. 42 (2016) 16697-16702, doi:10.1016/j.ceramint.2016.07.120.

[33] A Belous, O V'Yunov, D Mishchuk, S Kamba, D Nuzhnyy, Effect of vacancies on the structural and relaxor properties of $(\mathrm{Sr}, \mathrm{Ba}, \mathrm{Na}) \mathrm{Nb}_{2} \mathrm{O}_{6}, \mathrm{~J}$. Appl. Phys. 102 (2007), doi:10.1063/1.2752551 014111.

[34] W Cai, C Fu, J Gao, H Chen, Effects of grain size on domain structure and ferroelectric properties of barium zirconate titanate ceramics, J. Alloys Compd. 480 (2009) 870-873, doi:10.1016/j.jallcom.2009.02.049.

[35] L Wang, W Sui, S Luan, R Song, J Tan, Sintering behavior and dielectric properties of Ce doped strontium barium niobate ceramics with silica sintering additive, Mater. Chem. Phys. 134 (2012) 531-535, doi:10.1016/ j.matchemphys.2012.03.028.

[36] P Dhak, D Dhak, M Das, P Pramanik, Dielectric and impedance spectroscopy study of $\mathrm{Ba}_{0.8} \mathrm{Bi}_{2.133} \mathrm{Nb}_{1.6} \mathrm{Ta}_{0.4} \mathrm{O}_{9}$ ferroelectric ceramics, prepared by chemical route, J. Mater. Sci. Mater. Electron. 22 (2011) 1750-1760, doi:10.1007/ s10854-011-0358-1.

[37] I A Santos, D U Spínola, D Garcia, J A Eiras, Dielectric behavior and diffuse phase transition features of rare earth doped $\mathrm{Sr}_{0.61} \mathrm{Ba}_{0.39} \mathrm{Nb}_{2} \mathrm{O}_{6}$ ferroelectric ceramics, J. Appl. Phys. 92 (2002) 3251-3256, doi:10.1063/1.1481210.

[38] V V Shvartsman, W Kleemann, T Łukasiewicz, J Dec, Nanopolar structure in $\mathrm{Sr}_{\mathrm{x}} \mathrm{Ba}_{1-\mathrm{x}} \mathrm{Nb}_{2} \mathrm{O}_{6}$ single crystals tuned by $\mathrm{Sr} / \mathrm{Ba}$ ratio and investigated by piezoelectric force microscopy, Phys. Rev. B Condens. Matter 77 (2008), doi:10.1103/PhysRevB.77.054105 054105.

[39] A Surmin, P Fertey, D Schaniel, T Woike, Modulated structure of potassium sodium strontium barium niobates (KNSBN): harmonic solution, Acta Crystallogr. Sect. B Struct. Sci. B62 (2006) 228-235, doi:10.1107/ S0108768106001510.

[40] C J Huang, K Li, S Y Wu, X L Zhu, X M Chen, Variation of ferroelectric hysteresis loop with temperature in $\mathrm{Sr}_{\mathrm{x}} \mathrm{Ba}_{1-\mathrm{x}} \mathrm{Nb}_{2} \mathrm{O}_{6}$ unfilled tungsten bronze ceramics, J. Mater. 1 (2015) 146-152, doi:10.1016/j.jmat.2015.02.004.

[41] L Zhao, Q Liu, J Gao, S Zhang, J F Li, Lead-free antiferroelectric silver niobate tantalate with high energy storage performance, Adv. Mater. 29 (2017) 1701824, doi:10.1002/adma.201701824.

[42] X D Jian, B Lu, D D Li, Y B Yao, T Tao, B Liang, J H Guo, Y J Zeng, J Le Chen, S $\mathrm{G} \mathrm{Lu}$, Direct measurement of large electrocaloric effect in $\mathrm{Ba}\left(\mathrm{Zr}_{\mathrm{x}} \mathrm{Ti}_{1-\mathrm{x}}\right) \mathrm{O}_{3}$ ceramics, ACS Appl. Mater. Interfaces 10 (2018) 4801-4807, doi:10.1021 acsami.7b15933.

[43] X D Jian, B Lu, D D Li, Y B Yao, T Tao, B Liang, X W Lin, J H Guo, Y J Zeng, S $\mathrm{G} \mathrm{Lu}$, Enhanced electrocaloric effect in $\mathrm{Sr}^{2+}$-modified lead-free $\mathrm{BaZr}_{\mathrm{x}} \mathrm{Ti}_{1-\mathrm{x}} \mathrm{O}_{3}$ ceramics, ACS Appl. Mater. Interfaces 11 (2019) 20167-20173, doi:10.1021/ acsami.9b04036.

[44] P Wu, X Lou, J Li, T Li, H Gao, M Wu, S Wang, X Wang, J Bian, X Hao, Direct and indirect measurement of electrocaloric effect in lead-free $(100-\mathrm{x}) \mathrm{Ba}\left(\mathrm{Hf}_{0.2} \mathrm{Ti}_{0.8}\right) \mathrm{O}_{3}-\mathrm{x}\left(\mathrm{Ba}_{0.7} \mathrm{Ca}_{0.3}\right) \mathrm{TiO}_{3}$ ceramics near multi-phase boundary, J. Alloys Compd. 725 (2017) 275-282, doi:10.1016/j.jallcom.2017.07.103.

[45] C R Bowen, J Taylor, E Leboulbar, D Zabek, A Chauhan, R Vaish, Pyroelectric materials and devices for energy harvesting applications, Energy Environ. Sci. 7 (2014) 3836-3856, doi:10.1039/c4ee01759e.

[46] H Chen, S Guo, X Dong, F Cao, C Mao, G Wang, $\mathrm{Ca}_{\mathrm{x}} \mathrm{Sr}_{0.3}-\mathrm{xBa}_{0.7} \mathrm{Nb}_{2} \mathrm{O}_{6}$ lead-free pyroelectric ceramics with high depoling temperature, J. Alloys Compd. 695 (2017) 2723-2729, doi:10.1016/j.jallcom.2016.11.192.

[47] T Chen, S Y Wu, X Q Liu, X M Chen, A novel sol-gel route to synthesize $\left(\mathrm{Sr}_{0.5} \mathrm{Ba}_{0.5}\right) \mathrm{Nb}_{2} \mathrm{O}_{6}$ ceramics with enhanced electrocaloric effect, J. Adv. Dielectr. 7 (2017) 1750012, doi:10.1142/S2010135X17500126.

[48] A V Es'kov, S A Anokhin, M T Bui, O V Pakhomov, A A Semenov, P Y Belyavskiy, A B Ustinov, Investigation of the electrocaloric effect in strontium barium niobate (SBN) ceramics with rare-earth dopants, J. Phys. Conf. Ser. 1038 (2018) 012115.

[49] F Le Goupil, A-K Axelsson, M Valant, T Lukasiewicz, J Dec, A Berenov, N M Alford, Effect of Ce doping on the electrocaloric effect of SrxBa1-xNb2O6 single crystals, Appl. Phys. Lett. 104 (2014) 222911, doi:10.1063/1.4881842. 